

\title{
Finescale parameterizations of energy dissipation in a region of strong internal tides and sheared flow, the Lucky-Strike segment of the Mid-Atlantic Ridge
} Simon Pasquet, Pascale Bouruet-Aubertot, Gilles Reverdin, Andreas Turnherr, Lou St Laurent

\section{To cite this version:}

Simon Pasquet, Pascale Bouruet-Aubertot, Gilles Reverdin, Andreas Turnherr, Lou St Laurent. Finescale parameterizations of energy dissipation in a region of strong internal tides and sheared flow, the Lucky-Strike segment of the Mid-Atlantic Ridge. Deep Sea Research Part I: Oceanographic Research Papers, 2016, 12, pp.79-93. 10.1016/j.dsr.2015.12.016 . hal-01297448

\section{HAL Id: hal-01297448 \\ https://hal.sorbonne-universite.fr/hal-01297448}

Submitted on 4 Apr 2016

HAL is a multi-disciplinary open access archive for the deposit and dissemination of scientific research documents, whether they are published or not. The documents may come from teaching and research institutions in France or abroad, or from public or private research centers.
L'archive ouverte pluridisciplinaire HAL, est destinée au dépôt et à la diffusion de documents scientifiques de niveau recherche, publiés ou non, émanant des établissements d'enseignement et de recherche français ou étrangers, des laboratoires publics ou privés. 


\title{
Finescale parameterizations of energy dissipation in a region of strong internal tides and sheared flow, the Lucky-Strike segment of the Mid-Atlantic Ridge
}

\author{
Simon Pasquet, Pascale Bouruet-Aubertot*, Gilles Reverdin* \\ Sorbonne Universités- UPMC Univ. Paris 06- LOCEAN, France
}

Andreas Turnherr*

Lamont-Doherty Earth Observatory, Palisades, New York, USA

Lou St Laurent*

WHOI, Woods Hole, USA

\begin{abstract}
The relevance of finescale parameterizations of dissipation rate of turbulent kinetic energy is addressed using finescale and microstructure measurements collected in the Lucky Strike segment of the Mid-Atlantic Ridge (MAR). There, high amplitude internal tides and a strongly sheared mean flow sustain a high level of dissipation rate and turbulent mixing. Two sets of parameterizations are considered: the first ones (Gregg, 1989; Kunze et al, 2006) were derived to estimate dissipation rate of turbulent kinetic energy induced by internal wave breaking, while the second one aimed to estimate dissipation induced by shear instability of a strongly sheared mean flow and is a function of the Richardson number (Kunze et al, 1990; Polzin 1996).

The latter parameterization has low skill in reproducing the observed dissipation rate when shear unstable events are resolved presumably because there is no scale separation between the duration of unstable events and the inverse growth rate of unstable billows. Instead GM based parameterizations were
\end{abstract}

\footnotetext{
* Corresponding author

Email address: pascale.bouruet-aubertot@upmc.fr (Pascale Bouruet-Aubertot)
} 
found to be relevant although slight biases were observed. Part of these biases result from the small value of the upper vertical wavenumber integration limit in the computation of shear variance in Kunze et al (2006) parameterization that does not take into account internal wave signal of high vertical wavenumbers. We showed that significant improvement is obtained when the upper integration limit is set using a signal to noise ratio criterion and that the spatial structure of dissipation rates is reproduced with this parameterization.

Keywords: internal tides, turbulence, mixing, parameterization, mid-atlantic ridge

\section{Introduction}

Measurements of oceanic microstructure in areas of strong bathymetric variations often reveal enhanced turbulence. This includes sites such as canyons (Lueck and Osborn, 1985; St Laurent et al., 2001; Carter and Gregg, 2002), 5 seamounts (Nabatov and Ozmidov, 1988; Kunze and Toole, 1997; Lueck and Mudge, 1997) and hydraulically controled passages between basins (Roemmich et al., 1996; Polzin et al., 1996; Ferron et al., 1998; St Laurent and Thurnherr, 2007). This intensification of turbulent mixing leads to values of eddy diffusivity on the order of $10^{-3}-10^{-2} \mathrm{~m}^{2} \mathrm{~s}^{-1}$ that are 2-3 orders of magnitude larger than open ocean values. In most cases, both the breaking of internal waves and the instability of the low-frequency flow contribute to this intensification. Regions of strong variations of the bathymetry are indeed preferential sites for wave breaking. This breaking can be initiated by different processes, the most widely encountered in the scientific litterature being wave intensification near critical reflection, the increase in nonlinearities associated with the generation of harmonics when waves reflect at the bottom (e.g. Gerkema, 2006; Tabaei et al., 2005) and the generation of waves of small vertical scales that break locally (Munk, 1981).

Secondly local mixing can be strongly enhanced by the onset of shear in-

stability of the low-frequency motion passing over rough topographic structures 
(e.g. Stober et al, 2008). Typically this instability occurs as a result of flow acceleration through narrow passages. Other processes such as Lee wave generation and hydraulic control can ultimately lead to mixing.

Sills are typical regions where both processes are encountered. One of the most well-known example is the strait of Gibraltar as reported for instance by Farmer and Armi (1988) and Wesson and Gregg (1994). Also fractures zones on oceanic ridges are regions of high mixing, as they consist of small passages linking deep basins (Ferron et al., 1998; MacKinnon et al., 2008; Morozov et al., 2008).

Further measurements are required to improve our knowledge of the impact at a global scale of regions of rough topography on ocean mixing. This implies a quantification of mixing but also process studies of the link between dynamical processes leading to turbulence and turbulent mixing. The most accurate quan35 tification of mixing is obtained from microstructure measurements of shear or temperature at millimeter scale (Gregg, 1991). However as these measurements are quite rare, quantification of turbulent mixing largely relies upon finescale parameterization based on CTD (Conductivity Temperature Depth)/LADCP (Lowered Acoustic Dopler Current Profiler) data that are much more frequent 40 (e.g. Polzin et al, 2014).

Most finescale parameterizations used in the ocean interior first aimed to estimate mixing induced by convective instability and shear instability, either from the mean flow or from the internal wave field. Parameterizations based only on the mixing generated by the breaking of internal waves, have been widely applied over the last two decades. The dissipation rate of turbulent kinetic energy is then assumed to be equal to the rate of energy transfers within a weakly non linear internal wave field. In this case energy is transferred through resonant interactions between wave triads and the rate of energy transfers scales like the square of energy. These parameterizations, tested against microstructure measurements, were analyzed in light of the dynamics and progressively refined 
(see Polzin et al, 2014 for further details).

The first formulation of finescale parameterization based on shear instability resulting from wave-wave interactions and validation against microstructure measurements was performed by Gregg (1989). Using shear variance computed by differentiation over $10 \mathrm{~m}$, a consistency within a factor of 2 was obtained using four mid-latitude data sets. Later on, some studies revealed the inadequacy of Gregg (1989) to reproduce the observed dissipation in different dynamical situations (Wijesekera et al., 1993 [? ]; Kunze et al., 2002; MacKinnon and Gregg, 2005). This happens when the rate of energy transfer from large to breaking scales is not consistent with the assumed rate of wave-wave interaction. This can occur for instance when interaction with topography short-circuits the downscale cascade (Kunze et al., 2002) or when the highly variable nature of the coastal wavefield is not amenable in a general sense to statistical models of downscale energy transport (MacKinnon and Gregg, 2005). However, there are other situations where the parameterization might work in modified form, specifically in a form that accounts for a non-standard, e.g. non-GM, frequency content. Therefore, the choice of parameterization must rely on the energy distribution of the internal wave field as a function of frequency, namely on the shear to strain ratio. The idea was to take into account non-GM internal wave fields, with the introduction of a new factor involving shear to strain variance ratio (Henyey, 1991). Note that this ratio is an estimate of the frequency content of the internal wave field. Polzin et al. (1995) proposed to apply a factor in order to take into account the deviation of the frequency spectrum of the observed internal wave field from the GM frequency spectrum. Involving the shear/strain ratio led to a better collapse between results and observations according to Polzin et al. (1995). Next, Gregg et al.(2003) explicitly tested the dependence of latitude on dissipation rate using a large set of data.

The Polzin et al.(1995) method has been applied to different regions and these studies have shown that the shear and strain variances are significantly underestimated when $10-100 \mathrm{~m}$ velocity shear and isopycnal strain are omitted from the calculations because of the low signal to noise level in this scale range 
(Kunze et al., 2002). gust 2006. This is a region of strong mixing as evidenced by microstructure measurements (St Laurent and Thurnherr, 2007). Near the bottom, dissipation rate can be locally a factor of 100 higher than open ocean values. Finescale

Another issue raised by Polzin et al.(2002) is the bias introduced by the attenuation of LADCP shear data at vertical scales smaller than $150 \mathrm{~m}$. To compensate for this, they proposed corrections based on comparisons with XCP data. These corrections were next introduced in the parameterization and applied extensively by Kunze et al.(2006).

In order to improve shear variance estimate by taking into account small vertical scales (typically smaller than $50 \mathrm{~m}$ ), different authors integrate spectral shear up to a cut off wavenumber that depends on the shear to noise ratio. For instance Naveira Garabato et al. (2004) applied this method in the Nordic Seas, a region of weak stratification and fairly high noise level, and found a significant improvement in the estimates of eddy diffusivities.

Previous studies have shown that finescale parameterizations are sensitive to the shear and strain rate of underlying turbulent processes. As those are strongly related to local bathymetry, regions of small scale steep topography that coincide with regions of strong mixing are a challenge. The Mid-Atlantic ridge is one of these regions, filled with narrow passages linking deeper bassins, and often associated with overflows, that can be hydraulically controlled (Thurnherr et al., 2008; Polzin et al., 1996; Hogg et al., 1982; Ferron et al., 1998). A better understanding of the mechanisms leading to mixing in these passages and testing finescale parameterizations against microstructure measurements would significantly improve our understanding of the mixing generated along the MAR, which is the largest rough topographic feature in the ocean.

To answer these questions, we analyzed a data set collected near the LuckyStrike sub-marine volcano in the middle of a narrow passage connecting two north-south deep basins of the MAR, during the GRAVILUCK cruise in Au- 
measurements were performed prior to every microstructure profile. We take passage. Also a few repeated profiles were collected in the northern and southern 
basins to investigate semi-diurnal tides. Among these CTD/LADCP profiles, eleven were performed just after the deep microstructure profiler deployment vertical profile of $\epsilon$ was interpolated on a $1 \mathrm{~m}$ grid (St Laurent and Thurnherr, $2007)$. Due to instrument vibrations, a noise level of $(0.5-1) \times 10^{-10} \mathrm{~W}_{k} \mathrm{~kg}^{-1}$ 
applies to the estimates of $\epsilon$ reported for this study. For bulk Richardson numto shear and $N^{2}$ computation in order to avoid high frequency noise.

\section{The Lucky Strike segment: overview and dynamics}

The analysis of GRAVILUCK data provided an overview of the dynamics, both of the low frequency, sub-inertial, flow of deep waters and of super-inertial frequency motions. The deep flow has been characterized from all LADCP profiles collected during the cruise and from one-year mooring data in the eastern passage (Pasquet et al, 2011). In summer 2006, the deep flow is directed northward and extends up to $1400 \mathrm{~m}$ as reported in St Laurent and Thurnherr (2007). Currents are on the order of $10 \mathrm{~cm} \cdot \mathrm{s}^{-1}$ at the sill, and can reach values close to $20 \mathrm{~cm} \cdot \mathrm{s}^{-1}$ downstream but more importantly the current is strongly sheared (Fig 2) and possibly subject to shear instabilities. CTD profiles at the site showed that the stratification is uniform between $100 \mathrm{~m}$ and $800 \mathrm{~m}$ within a factor of two, and decreases with depth below 900m towards the bottom (Fig 3), roughly coinciding with the summits of the rift valley walls. Thurnherr et al. (2008) showed that the valley region was significatively less stratified than the external ridge flanks at the same depth. The along-stream density structure is characteristic of an hydraulically controlled flow, a typical situation for sub marine Valleys. This assumption has been confirmed by St Laurent and Thurnherr (2007), who found critical Froude numbers near the sill.

The one-year mooring data indicate that, as expected, the deep water flow is most of the time northward while a reversed southward flow is often observed at intermediate depth (Pasquet et al, 2011). The depth of reversal varies with time, typically within $[100,600] \mathrm{m}$ height above bottom at the sill.

At higher frequencies, the dynamics are dominated by semi-diurnal tides. They were best characterized during the cruise near the sill by bottom mounted ADCP data. The barotropic semi-diurnal tidal flow is clearly present on the along channel velocity component while the across channel velocity component reveals a 
more baroclinic structure (not shown).

Further information on internal tides was collected during the cruise from

the first $200 \mathrm{~m}$ above bottom (Fig.7). Downstream, diffusivities are between $\left[10^{-3}, 10^{-2}\right] \mathrm{m}^{2} \mathrm{~s}^{-1}$, with a decrease of two orders of magnitude in the water column above it. There diffusivities are smaller though significant with an 
average value of $\sim 10^{-4} \mathrm{~m}^{2} \cdot \mathrm{s}^{-1}$. The latter could reflect mixing induced by

\subsubsection{Gregg 1989 parameterization}

The first finescale parameterization was proposed by Gregg (1989) (11), who used the HWF model (Henyey et al, 1986) to estimate $\epsilon$. It is defined as:

$$
\epsilon_{\mathrm{Gregg} 89}=7 \times 10^{-10}\left\langle N^{2} / N_{0}^{2}\right\rangle\left\langle S_{10}^{4} / S_{G M}^{4}\right\rangle \mathrm{W} \cdot \mathrm{kg}^{-1}
$$

inferred from the Richardson number. Statistics of $R i$ number showed that $39 \%$ of Ri number are below the critical value within the first $500 \mathrm{~m}$ above the bottom while the percentage decreases down to $6 \%$ elsewhere. This could reflect the role of shear instability of the mean flow and internal waves as one of the major mechanism for mixing within a few hundred meters above the bottom.

\section{Finescale Parameterizations}

As the dynamics combine both strong internal tides and a mean shear flow, two kinds of parameterizations were tested here. We tested Garrett and Munk (GM) based parameterizations, in which shear and strain variances are compared to GM values (Garrett and Munk, 1975). We test the application of these parameterizations in situations of high energy levels and small-scale internal waves typical of the LS area. Secondly, a parameterization based on the Richardson number, which aimed to estimate dissipation induced by shear instability, is also tested.

\subsection{GM based parameterizations} for consistency for the comparison with the Kunze et al (2006) parameterization, $N$ is the buoyancy frequency, $N_{0}$ is the GM buoyancy frequency set to $5.2 \times 10^{-3} \mathrm{~s}^{-2}, S_{10}$ is the current shear estimated by differentiation over $10 \mathrm{~m}$ and $S_{G M}$ is the GM current shear equivalent to $1.91 \times 10^{-5}\left(\frac{N}{N_{0}}\right)^{2}$. This parameterization expressed in terms of shear normalized with GM assumes a constant 
shear to strain ratio, $R_{\omega}$, equal to that of GM. In fact this ratio varies with the frequency content of the internal wave field. To take this effect into account, Polzin et al (1995) introduced an additional factor to $\mathrm{G} 89, h\left(R_{\omega}\right)$ (see as well Kunze et al, 2006; Gregg et al, 2003). The parameterization then reads (e.g., 265 Cuypers et al, 2012):

$$
\epsilon=h\left(R_{\omega}\right) \epsilon_{\text {Gregg89 }}
$$

where $R_{\omega}$ is the square of the shear to strain ratio. $R_{\omega}$ is computed following the procedure described in Kunze et al (2006) with shear spectra computed over $320 \mathrm{~m}$ segments while strain spectra are computed over $256 \mathrm{~m}$ segments, it is given by:

$$
R_{\omega}=\left(\frac{\int_{I_{1}} S\left[V_{z} / \bar{N}\right] d k_{z}}{\int_{I_{2}} S\left[\xi_{z}\right] d k_{z}}\right)_{G M}
$$

270

with $I_{1}=\left[\frac{2 \pi}{320}, \frac{2 \pi}{150}\right] \mathrm{rad}^{-1} \mathrm{~m}^{-1}$ and $I_{2}=\left[\frac{2 \pi}{150}, \frac{2 \pi}{10}\right] \mathrm{rad}^{-1} \mathrm{~m}^{-1}, S\left[V_{z} / \bar{N}\right]$ and $S\left[\xi_{z}\right]$ are the buoyancy normalized shear and strain spectra, respectively. Each factor is normalized by its GM counterpart, as indicated with 'GM'. The upper integration limit for shear is chosen in order to avoid instrument noise at smaller wavelengths while the lower integration limit for strain is chosen to avoid contamination by background stratification (see appendix for details). $h(R \omega)$ is given by:

$$
h\left(R_{\omega}\right)=\frac{3\left(R_{\omega}+1\right)}{2 \sqrt{2} R_{\omega} \sqrt{R_{\omega}-1}}
$$

This formulation, eq.(2), is more appropriate than the original one as shown for instance by Cuypers et al (2012). In Cuypers et al (2012) measurements were performed in the Mediterranean Sea within anticyclonic eddies where the internal wave field strongly departs from the GM internal wave field. They validated this formulation against microstructure measurements performed within the upper $100 \mathrm{~m}$ including the seasonal pycnocline. Note that the factor $h(R \omega)$ is smaller than 1 in in the bottom boundary layer where the shear to strain ratio is higher than the GM value, which could lead to an underestimate of $\epsilon$. Hence 285 we tested an hybrid formulation:

$$
\epsilon_{G 89}=\max (h(R \omega), 1) \epsilon_{\mathrm{Gregg} 89}
$$


We tested another method computing vertical shear using a spectral method in order to avoid side effects of finite differencing (which are compensated by a 2.11 factor as expressed in equation (24) in Gregg, 1989) and applying a low-pass filter with a $1 / 32 m^{-1}$ cutoff. To do so, we compute the Fast Fourier Transform (Fast Fourier Transform) of the whole velocity profile, we then set to zero in Fourier space all length scales smaller than $32 \mathrm{~m}$. The shear is obtained in Fourier space by multiplying by $k_{z}$. The final shear profile is obtained by taking the inverse FFT. The $32 \mathrm{~m}$ GM shear variance is computed instead of the 10m GM shear variance for consistency (see eq.(1)).

\subsubsection{Kunze et al (2006) parameterization}

We tested a modified version of the parameterization first introduced by Gregg et al. (2003) and modified by Kunze et al. (2006) in which the shear variance is computed in spectral space. Following Kunze et al (2006) we first compute diapycnal diffusivity, $K_{K 06}$ which is given by:

$$
K_{\mathrm{K} 06}=K_{0} \frac{\left\langle V_{z}^{2}\right\rangle^{2}}{\left\langle V_{z}^{2}\right\rangle_{G M}^{2}} j(f / N) h\left(R_{\omega}\right)
$$

$V_{z}^{2}$ is the shear variance which is obtained by integrating the shear spectrum on the vertical wavenumber interval $\left[\frac{2 \pi}{320} \mathrm{rad} . \mathrm{m}^{-1} ; \frac{2 \pi}{150} \mathrm{rad}^{-1} \mathrm{~m}^{-1}\right]$ and the following terms are defined as follows:

$$
\begin{aligned}
K_{0} & =5 \times 10^{-6} \mathrm{~m}^{2} \cdot \mathrm{s}^{-1} \\
j(f / N) & =\frac{f \cosh ^{-1}(N / f)}{f_{30} \cosh ^{-1}\left(N_{0} / f_{30}\right)}
\end{aligned}
$$

$f$ is the Coriolis parameter, $\mathrm{f}_{30}$ is the Coriolis value at $30 \mathrm{~N},(8)$ takes into account the variation with latitude (Gregg et al., 2003). Note that we have taken into account in our calculation the corrections of LADCP shear proposed by Polzin et al. (2002) and Thurnherr et al. (2012) (see appendix for further details).

Dissipation rate is then inferred as:

$$
\epsilon_{\mathrm{K} 06}=5 K_{0} K_{\mathrm{K} 06} \bar{N}^{2}
$$


with $\bar{N}^{2}$ is the buoyancy frequency square averaged over the $320 \mathrm{~m}$ length segment.

4.1.3. Criterion for the definition of an upper integration limit for the computation of shear variance in Kunze et al (2006)

The vertical wavenumber cutoff of $\frac{2 \pi}{150} \mathrm{rad} . \mathrm{m}^{-1}$ defined by Kunze et al (2006) was chosen to be sufficiently small to avoid noise contamination. On the other hand shear variance might be underestimated if shear increases for high vertical wavenumbers beyond the upper integration limit. Thus the criterion should define the largest upper integration limit while keeping a reasonable signal to noise ratio. We discuss here the procedure to find out such a criterion. For that we will consider averaged shear spectra which are computed over two depth intervals, from 0 to $300 \mathrm{~m}$ above the bottom and from $300 \mathrm{~m}$ above the bottom 325 to the surface (Fig 8 ). Averaged shear spectra from 0 to $300 \mathrm{~m}$ above the bottom are clearly more energetic than averaged shear spectra further up and they are well above GM spectra. In both cases their shape is similar: spectra are blue for length scale larger than $100 \mathrm{~m}$, and are white between $100 \mathrm{~m}$ and $\sim 30 \mathrm{~m}$. The strong increase of the shear beyond $30 \mathrm{~m}$ is due to the increase in noise. It is thus clear that shear variance computed with an upper integration limit of $\frac{2 \pi}{150}$ will be underestimated but that the upper integration limit should not exceed $\sim 30 \mathrm{~m}$ to avoid noise contamination.

Hence we define in the following a criterion for the wavenumber cut-off based on signal to noise ratio, following Naveira Garabato et al. (2004). To compute noise spectra we took a rms noise of individual measurements of $3.2 \mathrm{~cm} . \mathrm{s}^{-1}$ (Polzin et al., 2002) with a correction factor of $\sqrt{3}$ applied by Kunze et al. (2006) and a spectral correction (From Thurnherr, 2012 and appendix), leading to the following expression for the vertical wavenumber noise spectrum:

$$
S_{\text {noise }}=\frac{3 \times\left(3.2 \mathrm{~cm} \cdot \mathrm{s}^{-1}\right)^{2} \times k_{z}^{2}}{120 \times \bar{N}^{2}} \frac{1}{\operatorname{sinc}^{8}\left(\frac{k_{z} \times 8}{2 \pi}\right)}
$$

In their study, Naveiro-Garabato et al. (2004) used a signal to noise ratio $(S N)$ of 3 as the criterion to define the upper integration limit. The same criterion 
applied on our data led to a majority of $k_{c}$ beyond $\frac{2 \pi}{32} \mathrm{rad}_{\mathrm{m}} \mathrm{m}^{-1}$. This is an issue as this scale is close to the bin size $(8 m)$, leading to a strong dependence on the spectral corrections. We therefore decided to use instead $S N=5$, which led to an upper integration limit usually on the order of $\frac{2 \pi}{32} \mathrm{rad}^{-m^{-1}}$ (see Fig 8 ). In the cases where the upper integration limit defined by $S N=5$ exceeds $\frac{2 \pi}{32} \mathrm{rad}^{-1} \mathrm{~m}^{-1}$, we took this value to avoid any influence of spectral corrections on our estimates. Note that this wavenumber domain should encompass the typical scale of vertical shear as inferred from Figures 4 and 5 .

\subsection{Richardson number based parameterization}

We also investigated whether a parameterization based upon Richardson number would be adequate provided that shear instability is one of the main mechanisms leading to turbulence in the LS segment. As opposed to the last parameterizations involving a computation in spectral space, this parameterization leads to a local estimate of dissipation with a $32 \mathrm{~m}$ vertical resolution, to be compared with the length of the segments used in K06 equal to $320 \mathrm{~m}$.

Kunze, Williams and Briscoe (1990). We implemented the parameterization described in Kunze, Williams and Briscoe (1990) (KWB), and then tested by Polzin (1996). This parameterization aims at quantifying the rate of dissipation of turbulent kinetic energy produced by shear instability. The KWB parameterization is defined as follows:

$$
\epsilon_{K W B}=\frac{f r \Delta z^{2}}{96}\left\langle N^{3}\left(\frac{1}{R i}-\frac{1}{R i_{c}}\right)\left(\frac{1}{\sqrt{R i}}-\frac{1}{\sqrt{R i_{c}}}\right)\right\rangle
$$

where $f r$ is the fraction of the water column which is unstable $\left(R i<R i_{c}\right)$, $\Delta z$ is the interval over which $S^{2}$ and $N^{2}$ are computed $\left(\Delta z=8\right.$ here), $S^{2}=$

$\left(U_{z}^{2}+V_{z}^{2}\right)$ and the angle brackets represent an average of all unstable events over a segment. $R i_{c}$ is defined here to be the Richardson number criterion below which a dynamical event can be unstable. As in Polzin (1996), we tested the following values for $R i_{c}: 0.25,0.33,0.5$ and 1 . We adopt in the following $R i_{c}=1$ which resolves more unstable events. Dissipation is estimated over 

segments where more than $25 \%$ of unstable events are encountered are retained for the comparison. This restricts the comparison to the lower part of the water column, where most unstable events occur.

\section{Test of the parameterizations}

An overall comparison of the different parameterizations is first displayed with a scatter plot of the different $\epsilon\left(\epsilon_{K 06}, \epsilon_{K 06-S N}, \epsilon_{G 89}\right.$ and $\left.\epsilon_{K W B}\right)$ as a function of $\epsilon_{D M P}\left(\mathrm{Fig} 9\right.$ ). Notice that both $\epsilon_{G 89}$ and $\epsilon_{K W B}$ which are computed on a $10 \mathrm{~m}$ and $8 \mathrm{~m}$ vertical grid have been averaged over $320 \mathrm{~m}$ segments used for the calculation of $\epsilon_{K 06}$. We first compare the different parameterizations with scatter plots in Figure 9 and with quantitative information in Table 1.

GM based parameterizations reproduces rather well the dissipation as opposed to Ri based parameterization which significantly underestimates the dissipation rate through the whole water column (Fig 9). The small number of points (Fig 9 d) results from the fact that most unstable events resolved by our measurements are in the lower layer near the bottom where the typical scale of the instabilities is larger as a result of stronger shear and weaker stratification compared to the interior. $\epsilon_{G 89}$ and $\epsilon_{K 06}$ perform about the same (Fig 9 a and c, Table 1) though slight differences are observed: $\epsilon_{G 89}$ tends to underestimate $\epsilon_{D M P}$ in the interior whereas $\epsilon_{K 06}$ tends to underestimate $\epsilon_{D M P}$ in the lower part of the water column. The plot with $\epsilon_{K 06-S N}$ has less scatter compared to that of $\epsilon_{K 06}$ with predictions significantly improved in the lower part of the water column. This points out the contribution of small scale shear variance, not taken into account by $\epsilon_{K 06}$, that contributes to an adequate estimate of $\epsilon_{D M P}$ above the bottom.

The performance of the different parameterizations can be characterized as well with histograms of the ratio between $\epsilon$ parameterized and $\epsilon_{D M P}$, shown in Figure 10. Basic statistics have been performed with mean value, standard 
deviation and skewness in order to quantify the distributions. The histogram

405 measurements and parameterizations. A straight line, corresponding to the critical Richardson number, $R i=0.25$, is displayed as an indicator of shear instability. 
The general pattern of dissipation in $\left(N^{2}, S^{2}\right)$ space (Fig 11 a) shows different regions of high values. Starting from low stratification, the first region of high dissipation rate is obtained for the lowest stratification where $\frac{S}{N}$ is close to 1. This region corresponds mostly to the deepest layers, weakly stratified and strongly sheared. A second region of high dissipation rate is encountered for intermediate stratification and high shear. It is likely in these regions that shear contributes to the onset of wavebreaking for instance for semi-diurnal internal tides for which the shear to strain ratio is fairly large. Eventually a third region is obtained in the pycnocline, in the most stratified water, where the shear does not vary significantly. There the Richardson number is far above the critical value which suggests that wavebreaking occurs at smaller vertical scales than those resolved by our measurements. $\epsilon_{G 89}$ (Fig 11 , b) exhibits an overall wellreproduced pattern. $\epsilon_{G 89}$ better reproduces $\epsilon_{D M P}$ in regions of intermediate and strong stratification, which corresponds to the ocean interior. In regions of weak shear and intermediate stratification, $\epsilon_{D M P}$ is largely underestimated while in regions of high shear and low stratification it is largely overestimated. $\epsilon_{K 06}$ underestimates $\epsilon_{D M P}$ in most regions (Fig 11 a and b) while the general pattern of $\epsilon_{K 06-S N}$ best reproduces that of $\epsilon_{D M P}$ (Fig 11 a and d). In fact the most striking improvement with $\epsilon_{K 06-S N}$ is revealed by the distribution of $\epsilon$ in $\mathrm{N}^{2} / \mathrm{S}^{2}$ space (Fig 11. c). The highest values obtained for low $N^{2}$ high $S^{2}$ and high $N^{2}$ high $S^{2}$ are now close to the observed ones, though the same biases remain: an overestimation in the $R i<0.25$ region and a slight underestimation in the strong $\mathrm{N}^{2} /$ weak $\mathrm{S}^{2}$ region. More importantly the regions of strong dissipation occurring in the ocean interior, intermediate $N^{2}$ and $S^{2}$ values, that were not present with $\epsilon_{K 06}$ are now reproduced.

Contribution of shear and strain variance to turbulent dissipation. To assess the contribution of both shear and strain variances on the computed dissipation equation 9 is used. Shear variance is computed with an upper bound defined using the signal to noise ratio or up to a wavelength of $32 \mathrm{~m}$, whichever comes first. Strain variance is computed as explained in the appendix. Three cases are 
presented:

- a shear and strain based parameterization (using $\left.R_{\omega}\right), \epsilon_{K 06-S N}$

- a shear-only parameterization, with $h\left(R_{\omega}\right)=1$ in $\epsilon_{K 06-S N}$

- a strain-only parameterization, in which $\epsilon$ is defined as follows:

$$
\epsilon_{0} \frac{\left\langle\zeta_{z}^{2}\right\rangle^{2}}{\left\langle\zeta_{z}^{2}\right\rangle_{G M}^{2}} j(f / N)
$$

Analysis of scatter plots (Fig. 12 reveals that both shear-only based parameterizations and shear/strain based parameterization reproduce better the observed dissipation than the strain based parameterization, which exhibits more scatter. It is also worth noting that the most scattered points are encountered near the bottom in the strain based parameterization. Adding the strain variance to the shear only based parameterization slightly improved statistical aspects: rms and mean values of $\log _{10}\left(\frac{\epsilon}{\epsilon_{D M P}}\right)$ decrease from 0.42 to 0.4 and 0.19 to 0.12 respectively (Fig 13). Strain based parameterization on the other hand has rms value of 0.69 , more than with shear based parameterizations, but mean value is better (0.12). From that we conclude that shear based variance is the most important parameter in that kind of environment.

Maps of depth-integrated $\epsilon$ values. We provide an overview of the spatial structure of dissipation in Figure 14. Dissipation rate is averaged over two layers: the interior layer (100m-1000m) (Fig 14.a) and the deeper layer (typically 0-600 above bottom) (Fig 14 b). The values of dissipation inferred from the DMP and those predicted by K06 parameterization are displayed for comparison. Most of the averaged values vary within a factor of 10 at most. In the eastern canyon where most measurements have been performed along the axis of the canyon we notice a slight intensification of dissipation near the sill, in the narrowest part of the canyon. This structure is fairly well reproduced by the parameterization except for one profile. Note that a more detailed comparison would require further measurements performed exactly at the same location owing to the high 
variability of topography and flow in the area. Furthermore in the western passage there is an $\mathrm{E} / \mathrm{W}$ contrast with higher dissipation on the eastern part. This contrast is consistent with the flow that is most intense on the eastern part due to the influence of rotation. Interestingly this contrast is reproduced by the parameterization but dissipation values are slightly under-estimated as previously mentioned. In the ocean interior the range of dissipation value is reduced as the effect of bottom topography is weaker. $\epsilon_{K 06-S N}$ predicts dissipation within a good approximation (see for instance in the western passage).

\section{Conclusion}

The LS segment of the MAR is a region that combines different dynamical processes favoring the onset of turbulence with a mean flow strongly sheared and an energetic internal wave field dominated by semi-diurnal tides. As a consequence of these dynamics combined with the complex bathymetry, it is a region of intense mixing thus providing an ideal site for the validation of finescale parameterizations under conditions of high energy levels. We tested the validity of several finescale parameterizations of dissipation rate of turbulent kinetic energy by comparisons with microstructure measurements. We considered two sets of parameterizations: the first set was developed with the aim of estimating dissipation induced by internal wave breaking while the second one is a model developped for turbulence induced by shear instability and is based upon the Richardson number.

The latter parameterization had low skill in reproducing well enough the observed dissipation rates. In fact, the method provides relevant estimates provided that there is a scale separation between the duration of the unstable events and that of the inverse of the billows growth rate as mentioned by Polzin (1996). A failure of this condition might explain why KWB parameterization is not relevant with our dataset.

Instead the former set of parameterizations, derived from Kunze et al. (2006) 
and Gregg (1989), provided adequate estimates of $\epsilon_{D M P}$ in our dynamical context. The general pattern in $\left(N^{2}, S^{2}\right)$ space is fairly well reproduced though some biases are observed: $\epsilon_{G 89}$ tends to slightly overestimate $\epsilon_{D M P}$ in low stratification areas underestimate $\epsilon_{D M P}$ in low shear regions while K06 tends to slightly underestimate $\epsilon_{D M P}$ in most regions. The fact that K06 underestimates $\epsilon$ points out a generic problem, that of the estimate of shear variance. We find that with an upper integration limit of $\frac{2 \pi}{150} \mathrm{rad}^{-1}$ (as in Kunze et al, 2006) the contribution of high vertical wavenumbers which are significant here, is not taken into account. It is thus important to extend the wavenumber interval of integration by defining a cut-off wavenumber at which the shear to noise ratio is equal to a prescribed threshold. We find here that applying a criterion of signal over noise of 5 was essential to reproduce dissipation in regions of intermediate values of $N^{2}$ where internal waves and high vertical modes internal tides come into play. In comparison, Tian et al. (2009) and Naveira Garabato et al.(2004) used a threshold value of 3 for the computation of shear variance leading in their case to a cut-off vertical wavelength ranging from $50 \mathrm{~m}$ to $90 \mathrm{~m}$. In our case, we obtained an upper bound most of the time on the order of $30 \mathrm{~m}$ when we tried a shear to noise ratio set to 3 , indicating that our data were less noisy or more energetic.

This study allowed us to provide a guide line for improving finescale parameterizations in different dynamical environments. The first main point is that the integration interval for K06 parameterization must include the relevant vertical scales, namely here those of the high-order vertical modes that include the significant semi-diurnal internal tide. The second main point is that the factor taking into account deviation from the GM frequency spectrum is required to reproduce the impact of higher frequency waves observed in the upper layer. Also the overestimate of dissipation in regions of weak stratification where the Richardson number is close to critical points is observed for all parameteriza545 tions. This points out a generic problem in these situations for which wave wave interactions do not fulfill the theoretical framework of GM parameterizations. 
This might result from the reduced internal waves frequency range of internal waves combined with a high energy level. Apart from the weak stratification another factor is related to the canyon bathymetry which might lead to multiple internal wave reflections with enhanced interactions. In fact this was found in several studies when high energy level at finescale and/or weak stratification/ canyon finescale parameterization overestimate epsilon (e.g. Bouruet-Aubertot et al, 2010 for the former and Carter and Gregg, 2002 for the latter). Others studies showed the inadequacy of finescale parameterizations to estimate dissipation rate in canyons (e.g. Kunze et al, 2002) where other processes than wave wave interactions such as critical reflections, scattering by small scale topography, internal hydraulic jumps dominate. Instead these parameterizations work fairly well in the Lucky Strike area as inferred from our observations. This suggests that internal wave cascade processes are dominant in our observations. Another interesting result is that the slight modification introduced in the G89 parameterization, with a shear to strain ratio taken into account, widens its range of application, thus providing a $10 \mathrm{~m}$ estimate of dissipation that does not depend on spectral corrections. This method has been applied to a two mooring data set in the eastern passage at the sill and downstream, including ADCP and CTD measurements, to provide a temporal evolution of dissipation and mixing over a year (Pasquet et al, 2011; Pasquet et al, 2015).

\section{Appendix: Implementation of Kunze et al. (2006) parameterization}

We present in the following how we apply the procedure described by Kunze et al. (2006). We define 320-m segments for the shear and 256-m segments for the strain following Kunze et al. (2006). We then remove a linear trend on the velocity for each segment prior to the shear calculation and a quadratic trend on $\mathrm{N}^{2}$ for each segment. The strain is estimated as follows:

$$
\xi_{z} \approx \frac{N^{2}-\overline{N^{2}}}{\overline{N^{2}}}
$$

We apply a $10 \%$ Tukey window on the segments, prior to performing FFT. 
We get the following spectral densities for the normalized shear and for the strain:

$$
\begin{aligned}
S\left[V_{z} / \bar{N}\right] & =\frac{1}{\overline{N^{2}}} \times|f f t(V)|^{2} k_{z}^{2} \\
S\left[\xi_{z}\right] & =\left|f f t\left(\xi_{z}\right)\right|^{2}
\end{aligned}
$$

As underlined by Polzin et al. (2002), spectral corrections are required due to the smoothing induced by post processing of data and LADCP motions. As the data have been processed using Velocity Inversion method (Visbeck, 2002), we followed Thurnherr et al. (2012) to determine the spectral corrections. We therefore applied the the following expression considering the fact the size of the bins are $8 \mathrm{~m}$ :

$$
\operatorname{Shear}_{\text {Corr }}\left(k_{z}\right)=\operatorname{sinc}^{8}\left(\frac{k_{z} \times 8}{2 \pi}\right)
$$

taking into account depth binning, range averaging and superensemble preaveraging. According to Thurnherr (2012), instrument tilting doesn't need to be corrected, as the maximum spectral damping associated with instrument tilting in the vertical wavenumber range resolved by the LADCP remains below $10 \%$ in the case of bin size smaller than $10 \mathrm{~m}$. Note also that when spectral corrections are applied, we use downcast LADCP profiles only, as suggested by Thurnherr (2012).

For the strain, the spectral correction that takes into account the smoothing due to the interpolation operations reduces to:

$$
\operatorname{Strain}_{\mathrm{Corr}}=\operatorname{sinc}^{2}\left(\frac{k_{z} \times 2}{2 \pi}\right)
$$

We calculate the variances of shear and strain by integrating spectra over 600 the interval $I_{s h}=\left[\frac{2 \pi}{320} \mathrm{rad} . \mathrm{m}^{-1} \frac{2 \pi}{150} \mathrm{rad} . \mathrm{m}^{-1}\right]$ for the former and over the interval $I_{s t}=\left[\frac{2 \pi}{150} \mathrm{rad}^{-m^{-1}} \frac{2 \pi}{10} \mathrm{rad} . \mathrm{m}^{-1}\right]$ for the latter. 
We next compute the variance of these quantities associated with the Garrett and Munk model:

605

$$
\begin{aligned}
\left\langle V_{z}^{2}\right\rangle_{G M} & =\frac{3 \pi E_{0} b j_{*}}{2} \int_{I_{s h}} \frac{k_{z}^{2}}{\left(k_{z}+k_{z *}\right)^{2}} d k_{z} \\
\left\langle\xi_{z}^{2}\right\rangle_{G M} & =\frac{\pi E_{0} b j_{*}}{2} \int_{I_{s t}} \frac{k_{z}^{2}}{\left(k_{z}+k_{z *}\right)^{2}} d k_{z}
\end{aligned}
$$

with

$$
k_{z *}=\frac{\pi j_{*} N}{b N_{0}}
$$

with the following constants of the model:

610

- $E_{0}=6.310^{-5}(\mathrm{GM}$ dimensionless spectral level $)$

- $b=1300 \mathrm{~m}$ (Height scale of the thermocline)

- $J_{*}=3$ (Order of vertical mode)

- $N_{0}=5.210^{-3}$ rad.s ${ }^{-1}$ (Reference buoyancy frequency)

615

- $f$ being the inertial frequency

- $f_{30}$ being the inertial frequency at $30 \mathrm{~N}$.

We then compute the ratio of the normalized shear variance with the strain variance, called $R_{\omega}$. The value of this ratio is determined for linear internal waves by their frequency, the inertial frequency and the buoyancy frequency.

${ }_{620}$ Its general expression is:

$$
R_{\omega}=\frac{\left\langle V_{z}^{2}\right\rangle}{\bar{N}^{2}\left\langle\xi_{z}^{2}\right\rangle}
$$

Since normalized shear and strain variances are computed over a different wavenumber interval, $I_{s h}$ and $I_{s t}$, each variance is normalized by the GM variance. Note that $R_{\omega}$ can not be theoretically less than 1 for an internal wave $\left(R_{\omega}=1\right.$ for a ${ }_{625}$ wave with $\omega=N$ ). However, if this case is encountered in the calculations, $\epsilon$ is 
set to $\mathrm{NaN}$.

\section{Acknowledgments}

The measurements were performed during the GRAVILUCK cruise on French ship time funded by Ifremer and INSU and coordinated by Valérie Ballu. This project was funded by LEFE/IDAO INSU program. We acknowledge Claudie Marec and Antonio Lourenço for their technical support for CTD/LADCP measurements and post-processing of these data. We acknowledge Eric Kunze for providing details regarding the implementation of his parameterization and Yannis Cuypers for useful discussions.

\section{References}

Bouruet-Aubertot, P., van Haren, H., Lelong, M.P., 2010: Stratified intertial subrange from in-situ observations in the bottom boundary layer of the Rockall channel. J. Phys. Oceanogr., 40, 2401-2417.

Carter, G. S., Gregg, M. C., 2002: Intense, variable mixing near the head of Monterey submarine canyon. J. Phys. Oceanogr., 32, 3145-3165.

Cuypers, Y., Bouruet-Aubertot, P., Marec, C., Fuda, J.L.,2012: Characterization of turbulence and validation of a finescale parametrization in the Mediterranean Sea during the BOUM experiment Biogeosciences Discuss., 8,89618998.

Farmer, D., Armi, L., 1986: Maximal two-layer exchange over a sill and through the combination of a sill and contraction with barotropic flow. J. Fluid Mech., 164, 53-76.

Ferron, B., Mercier, H., Speer, K., Gargett, A., Polzin, K., 1998: Mixing in the Romanche Fracture Zone. J. Phys. Oceanogr., 28, 1929-1945. 
Firing, E. Lowered ADCP development and use in WOCE. It. WOCE Newsletter, 30:1014, 1998.

Garrett, C. J. R., Munk, W. H., 1975: Space-time scales of internal waves: A progress report. J. Geophys.Res., 80, 291-297.

Gerkema, T., 2006: Internal-wave reflection from uniform slopes: higher harmonics and Coriolis effects. Nonlin. Processes Geophys., 13, 265-273.

Gregg, M. C., 1989: Scaling turbulent dissipation in the thermocline. J. Geophys. Res., 94(C7), 96869698.

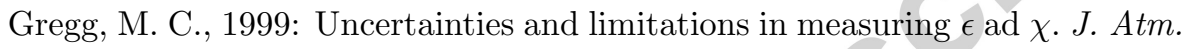
Ocean. Tech., 16, 1483-1490.

Gregg, M. C., Kunze, E., 1991: Shear and strain in Santa Monica basin. J. Geophys. Res., 96, 16709-16719.

Gregg, M. C., Sanford, T. B., Winkel, D. P., 2003: Reduced mixing from the breaking of internal waves in equatorial ocean waters. Nature, 422, 513-515.

Henyey, F. S., Wright, J., Flatte, S. M., 1986: Energy and action flow through the internal wave field. J. Geophys. Res., 91, 8487-8495.

Henyey, F. S., 1991: Scaling of internal wave model predictions for $\epsilon$. $D y$ namics of Oceanic Internal Gravity Waves, 'Aha Huliko' a Hawaiian Winter Workshop, P. Mller and D. Henderson, Eds., University of Hawaii at Manoa, 233-236.

670 Hogg, N., Biscaye, P., Gardner, W., and Schmitz Jr., W. J., 1982: On the transport and modification of Antarctic Bottom Water in the Vema Channel. J. Mar. Res., 40(Suppl.), 231-263.

Kunze, E., Williams III, A. J., Briscoe, M. G., 1990: Observations of shear and vertical stability from a neutrally buoyant float. J. Geophys. Res., 95(C10), 675 18127-18142. 
Kunze, E., Toole, J. M., 1997: Tidally driven vorticity, diurnal shear and turbulence atop Fieberling Seamount. J. Phys Oceanogr., 27, 2663-2693.

Kunze, E., Rosenfeld, L. K., Carter, G. S., Gregg, M. C., 2002: Internal waves in Monterey Submarine Canyon. J. Phys Oceanogr., 32, 1890-1913.

Kunze, E., Firing, E., Hummon, J. M., Chereskin, T. K., Thurnherr, A. M., 2006: Global abyssal mixing inferred from Lowered ADCP shear and CTD strain profiles. J. Phys Oceanogr., 36(8), 1553-1576.

Lueck, R. G., Mudge, T. D., 1997: Topographically-induced mixing around a shallow seamount. Science, 276, 1831-1833.

Lueck, R. G., Osborn, T. R., 1985: Turbulence measurements in a submarine canyon. Cont. Shelf Res., 4, 681-698.

MacKinnon, J. A., Gregg, M. C., 2005: Spring Mixing on the New England Shelf. J. Phys. Oceanogr., 35(12), 2425-2443.

MacKinnon, J. A., Shaun Johnston, T. M., Pinkel, R., 2008: Strong transport and mixing of deep water through the Southwest Indian Ridge. Nature Geosciences, 1, 755-758.

Morozov E.G., Demidov A.N., Tarakanov R.Yu., 2008: Transport of Antarctic waters in the deep channels of the Atlantic Ocean. Doklady Earth Sc., 423(8), 1286-1289.

Munk, W., 1981: Internal waves and small scale process. Evolution of Physical Oceanography, B. A. Warren and C. A. Wunsch, Eds., The MIT Press, 623 pp. Munk, W., Wunsch, C., 1998: Abyssal recipes II: Energetics of tidal and wind mixing. Deep-sea Res., 45, 1977-2010.

Nabatov, V. N., Ozmidov, R. V., 1988: Study of turbulence above seamounts in the Atlantic Ocean. Oceanology, 28, 161-166. 
Naveira Garabato, A. C., Polzin, K. L., King, B. A. K., Heywood, K. J., Visbeck, M., 2004: Widespread intense turbulent mixing in the Southern ocean. Science, 303(5655), 210-213.

Pasquet, S., Bouruet-Aubertot, P., Reverdin, G., 2011: Turbulent mixing in

the Lucky Strike segment of the MAR: temporal variability and mechanisms. Proc. Stratified Flows

Pasquet, S., Bouruet-Aubertot, P., Reverdin, G., Loureco, A., Turnherr, A., 2015: Transport and turbulent mixing inferred from mooring measurements in the Lucky Strike segment of the Mid-Atlantic ridge. In preparation

Polzin, K. L., 1996: Statistics of the Richardson Number: Mixing Models and Finestructure. J. Phys. Oceanogr., 26, 1409-1425.

Polzin, K. L., Toole, J. M., Schmitt, R. W., 1995: Finescale parameterizations of turbulent dissipation. J. Phys. Oceanogr., 25, 306-328.

Polzin, K. L., Speer, K. G., Toole, J. M., Schmitt, R. W., 1996: Intense mixing 715 of Antartic Bottom Water in the equatorial Atlantic Ocean. Nature, 380, 5457 .

Polzin, K. L., Hummon, J., Firing, E., 2002: The finescale response of lowered ADCP velocity profiles. J. Atmos. Oceanic Technol., 19, 205-223.

Polzin, K. L., Naveiro-Garabato, A., Huussen, T.N., Sloyan, B.M., Waterman, Res., 119, 1383-1419.

Roemmich, D., Hautala, S., Rudnick, D., 1996: Northward abyssal transport through the Samoan Passage and adjacent regions. J. Geophys Res., 101, 14039-14055.

725 St. Laurent, L. C., Toole, J. M., Schmitt, R. W. 2001: Buoyancy forcing by turbulence above rough topography in the abyssal Brazil Basin. J. Phys Oceanogr., 31, 3476-3495. 
St. Laurent, L. C., Thurnherr, A. M., 2007: Intense mixing of lower thermocline water on the crest of the Mid-Atlantic Ridge. Nature, 448, 680-683.

Stober, U., Walter, M., Mertens, C., Rhein, M., 2008 : Mixing estimates from hydrographic measurements in the Deep Western Boundary Current of the North Atlantic. Deep Sea Res., 55, 721-736.

Tabaei, A., Akylas, T. R., Lamb, K., 2005: Nonlinear effects in reflecting and colliding internal wave beams. J. Fluid Mech., 526, 217-243

735 Tian, J., Yang, Q., Zhao, W., 2009: Enhanced diapycnal mixing in the South China Sea. J. Phys. Oceanogr., 39, 3191-3203.

Thurnherr, A. M., 2012: The Finescale Response of Lowered ADCP Velocity Measurements Processed with Different Methods. J. Atm. Oc. Tech., 29, 597600.

${ }_{740}$ Thurnherr, A. M., Reverdin, G., Bouruet-Aubertot, P., St. Laurent, L. C. W., Vangriesheim, A., Ballu, V., 2008: Hydrography and flow in the Lucky Strike segment of the Mid-Atlantic Ridge. J. of Mar. Res., 66, 347-372.

Visbeck, M. 2002: Deep velocity profiling using Lowered Acoustic Doppler Current Profilers: Bottom track and inverse solutions. J. Atm. Oc. Tech., 19,

Wesson, J. C., Gregg, M. C., 1994: Mixing at Camarinal sill in the strait of Gibraltar. J. Geophys Res., 99 (C5), 9847-9878.

Wijesekera, H., Padman, L., Dillon, T., Levine, M., Paulson, C., Pinkel, R., 1993: The application of internal-wave dissipation models to a region of strong

mixing. J. Phys. Oceanogr., 23, 269-286.

\section{Figures}






Figure 1: Bathymetry of the area of study. The submarine volcano in the center is surrounded by 2 passages linking 2 deep basins to the north and south. DMP profiles (blue) and CTD/LADCP profiles (red) were made along the eastern passage and across the western passage. 




Figure 2: Mean currents along the eastern passage. Red arrows are 50m averaged processed LADCP data. Yellow arrows are two-week averaged velocities recorded by a bottom mounted ADCP. 


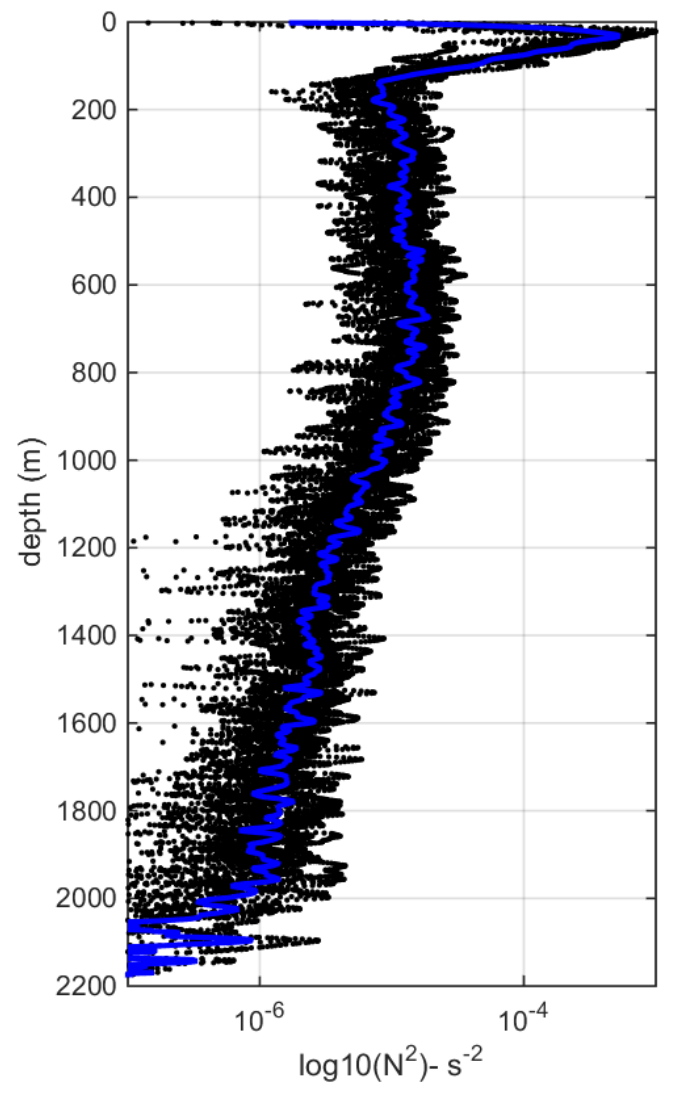

Figure 3: Mean $\mathrm{N}^{2}$ profiles in $\mathrm{s}^{-2}$ from $11 \mathrm{CTD}$ casts (blue curve), individual points from all 11 profiles are displayed as well (black points). 



Figure 4: a) Baroclinic eastward velocity in the northern basin at $t_{0}$ (in blue) and $t_{0}+6 h$ (in red) as a function of depth. b) same as in a) but in the southern basin. 

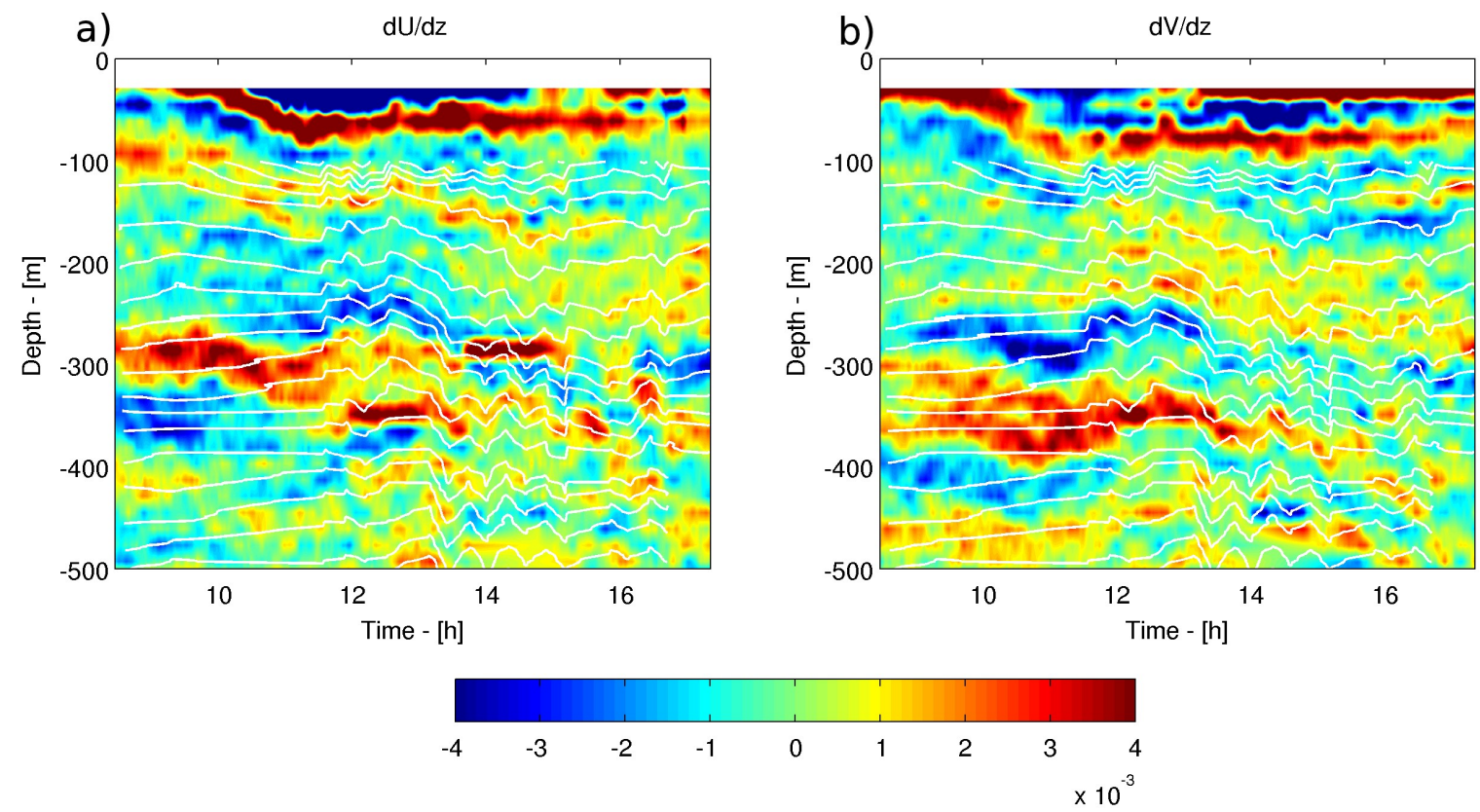

Figure 5: Shear of the U component (a) and the V component (b) in $s^{-1}$ from ship mounted ADCP, over the top $500 \mathrm{~m}$ during 9 hours. Isopycnals from repeated CTD casts are superimposed in white lines. 




Figure 6: Profiles of dissipation along the eastern passage. Profiles of dissipation (blue) are plotted on a logarithmic axis. The colorbar denotes $\log 10(1 / \mathrm{Ri})$. The downstream direction of the deep layer flow is toward the right. 


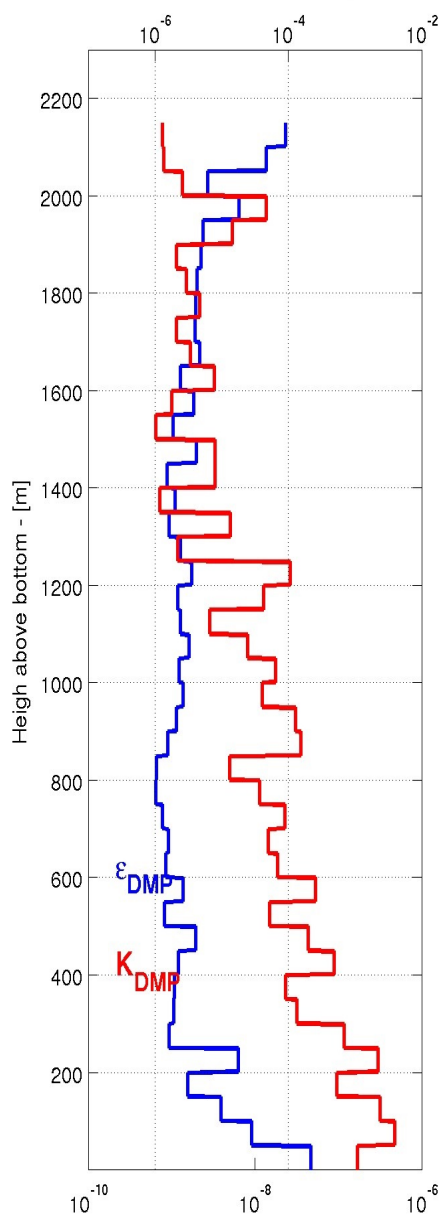

Figure 7: Profiles of dissipation (blue) and eddy diffusivity (red) averaged along the eastern passage on $50 \mathrm{~m}$ segments. Profiles are plotted on a logarithmic axis and are functions of height above bottom (HAB). Dissipation rate from the DMP is displayed in blue $\left(W \cdot \mathrm{kg}^{-1}\right)$ and diapycnal diffusivity is displayed in $\operatorname{red}\left(m^{2} \cdot s^{-1}\right)$. 


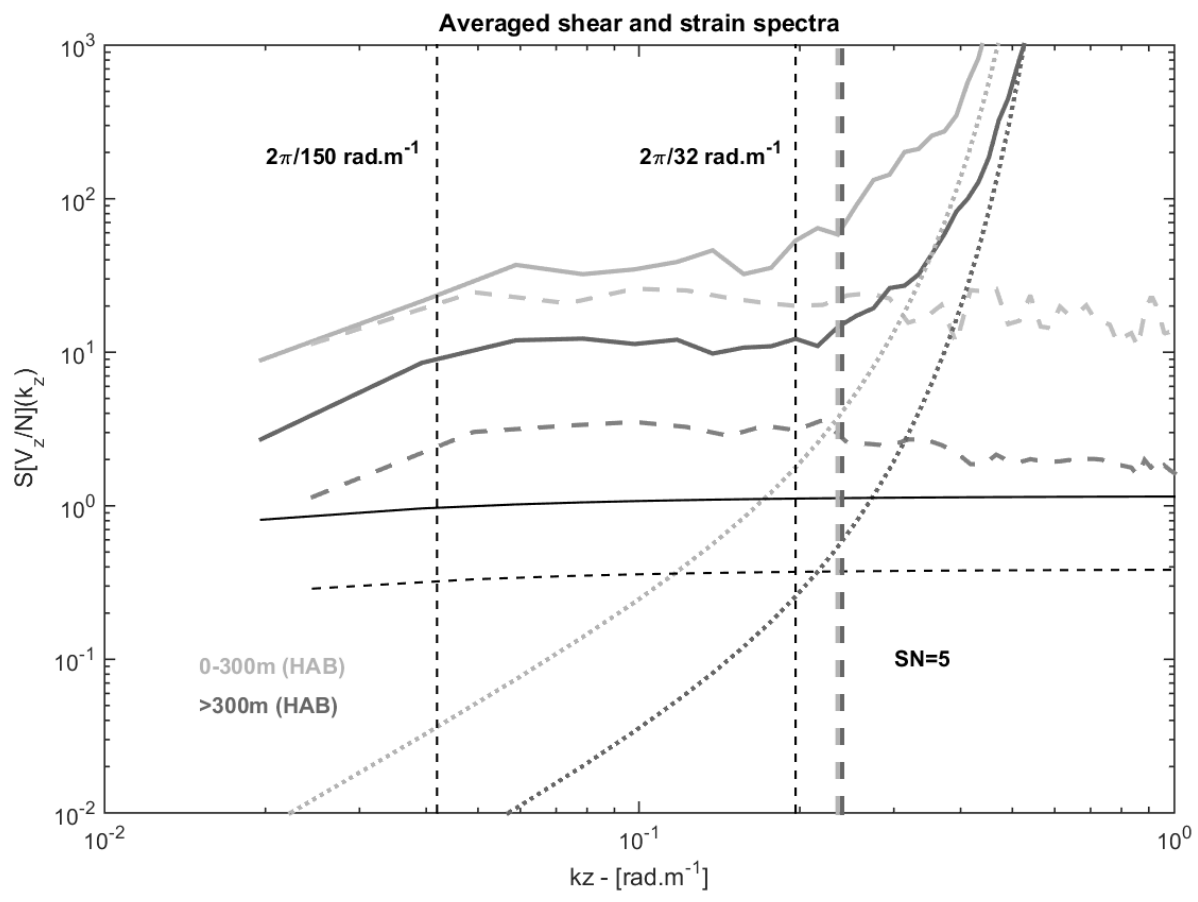

Figure 8: Vertical wavenumber spectra of normalized shear corrected with 14 (bold,solid lines), vertical wavenumber spectra of GM shear (thin, solid line), vertical wavenumber spectra of strain (dashed lines) and modelled noise spectra of the shear calculated with 10 (dotted lines). The vertical dashed lines denote where the ratio between averaged shear spectra and modelled noise spectra, $S N$, is equal to 5 . Vertical wavenumbers of $\frac{2 \pi}{150} \mathrm{rad}^{-1}$ and $\frac{2 \pi}{32}$ rad. $\mathrm{m}^{-1}$ are shown with thin vertical dashed lines. Shear spectra averaged over the first $300 \mathrm{~m}$ above the bottom are in grey, and black refers to an average over shallower depths. 
a)

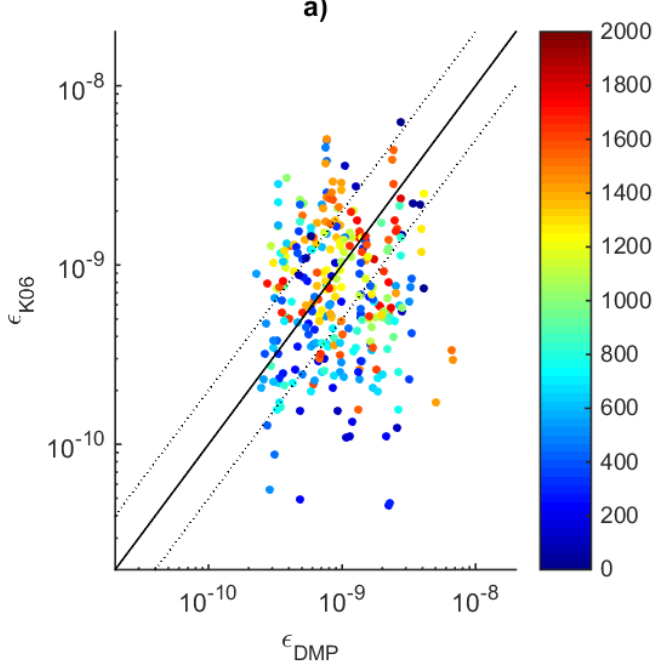

c)

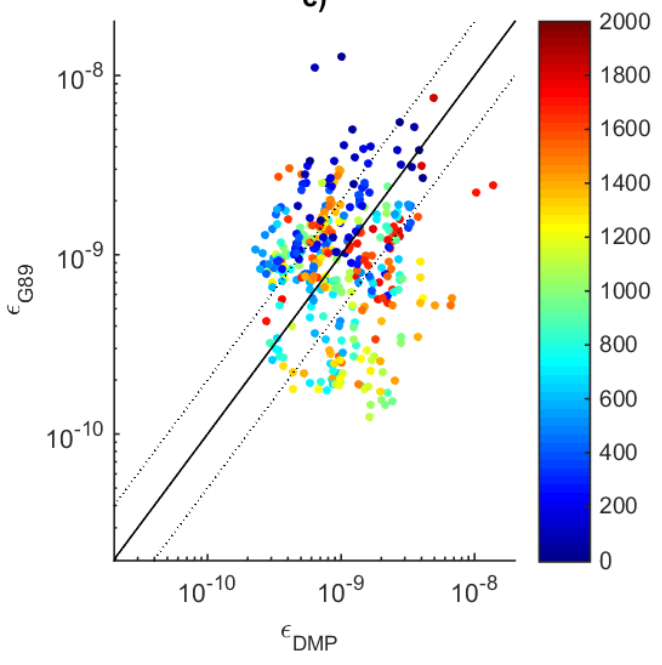

b)

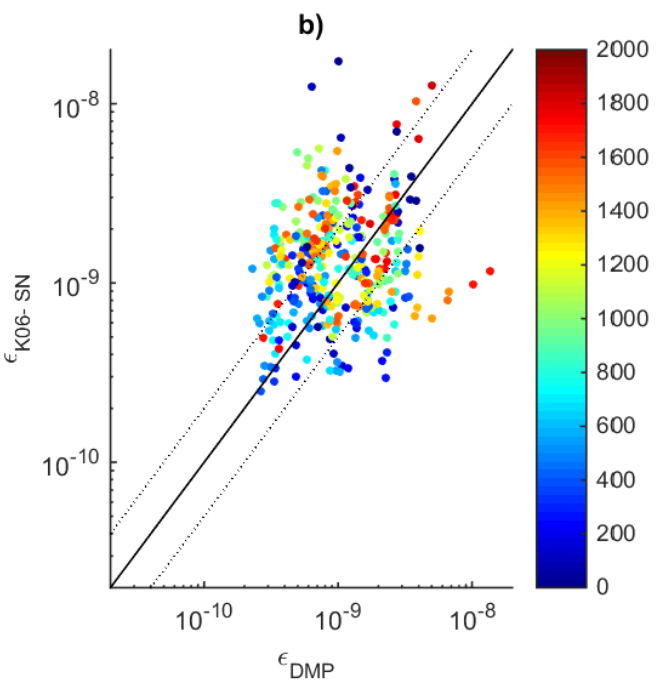

d)

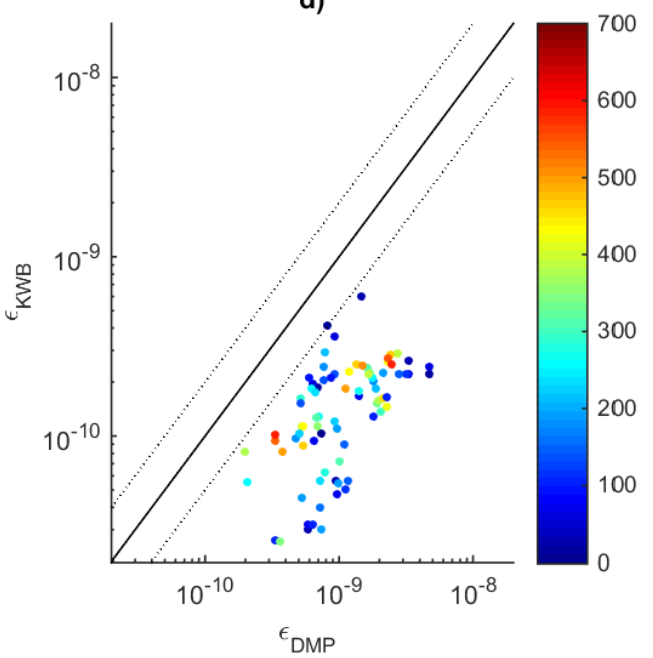

Figure 9: Scatter plots of parameterizations as a function of $\epsilon_{D M P}$ from $\epsilon_{K 06}$ (a), $\epsilon_{K 06-S N}$ (b), $\epsilon_{G 89}$ (c) and $\epsilon_{K W B}$ (d) compared to the dissipation measured by the DMP. The two dotted lines delimit the area where the ratio between $\epsilon$ from the parameterizations and observation is less than a factor of 2 . The colorbar denotes the height above bottom. 

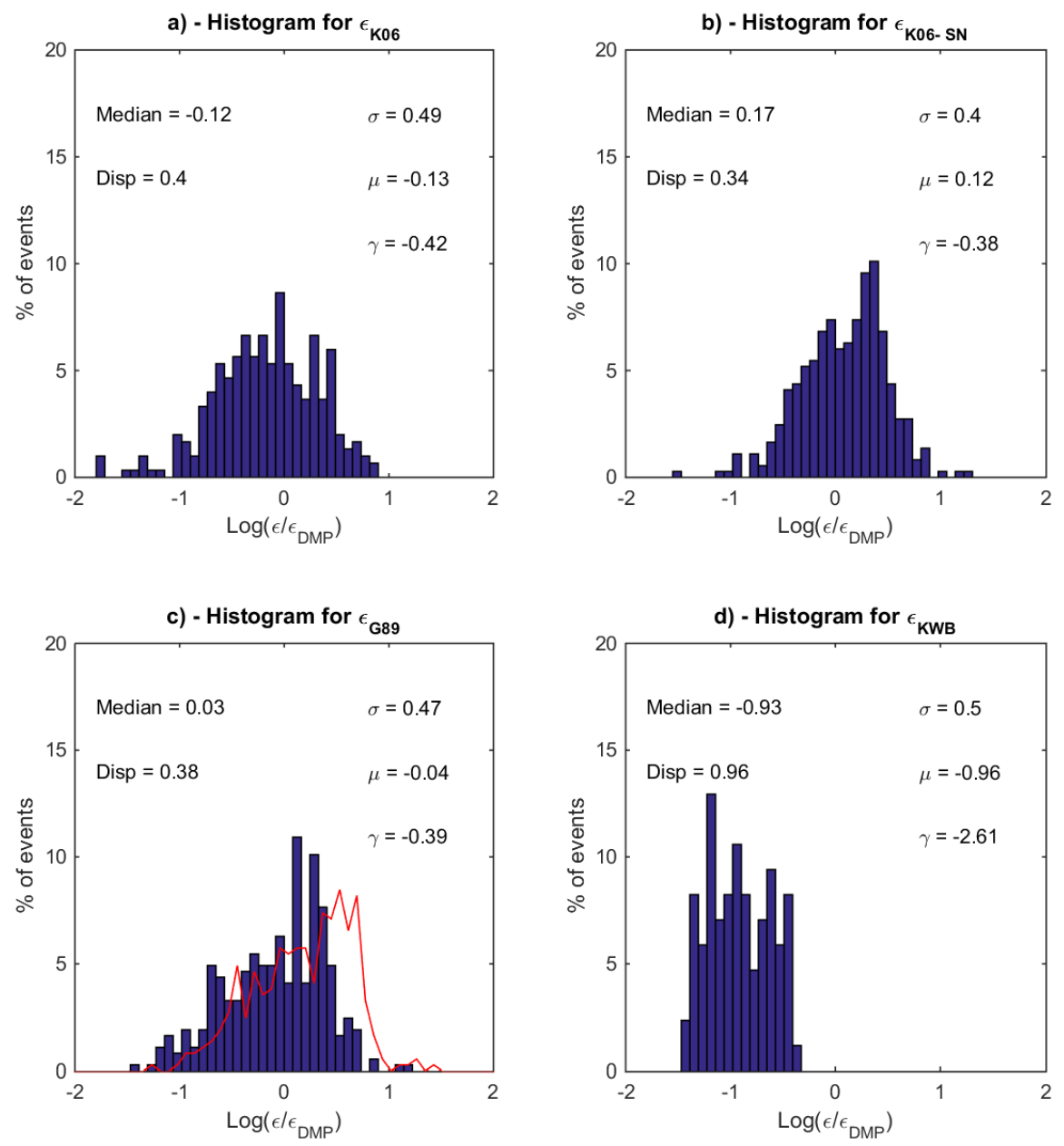

Figure 10: Histogram of the logarithm of the ratio between $\epsilon$ parameterized and $\epsilon$ observed for the 4 following parameterizations: $\epsilon_{K 06}$ (a), $\epsilon_{K 06-S N}$ (b), $\epsilon_{G 89}$ (c) and $\epsilon_{K W B}$ (d). The $\mathrm{x}$-axis is the logarithm of the ratio. Mean value, $\mu$, standard deviation, $\sigma$, and skewness, $\gamma$ are indicated in each case. The red curve refers to the histogram of Gregg89 computed using the FFT method described in section 4 . 



40

Figure 11: Distribution in the $\left(N^{2}, S^{2}\right)$ space of $\epsilon_{D M P}(\mathrm{a}), \epsilon_{G 89}$ (b), $\epsilon_{K 06}$ (c) and $\epsilon_{K 06-S N}$ (d). The averages were performed over $320 \mathrm{~m}$ segments. The black line represents the threshold value of Richardson number $(\mathrm{Ri}=0.25)$. 

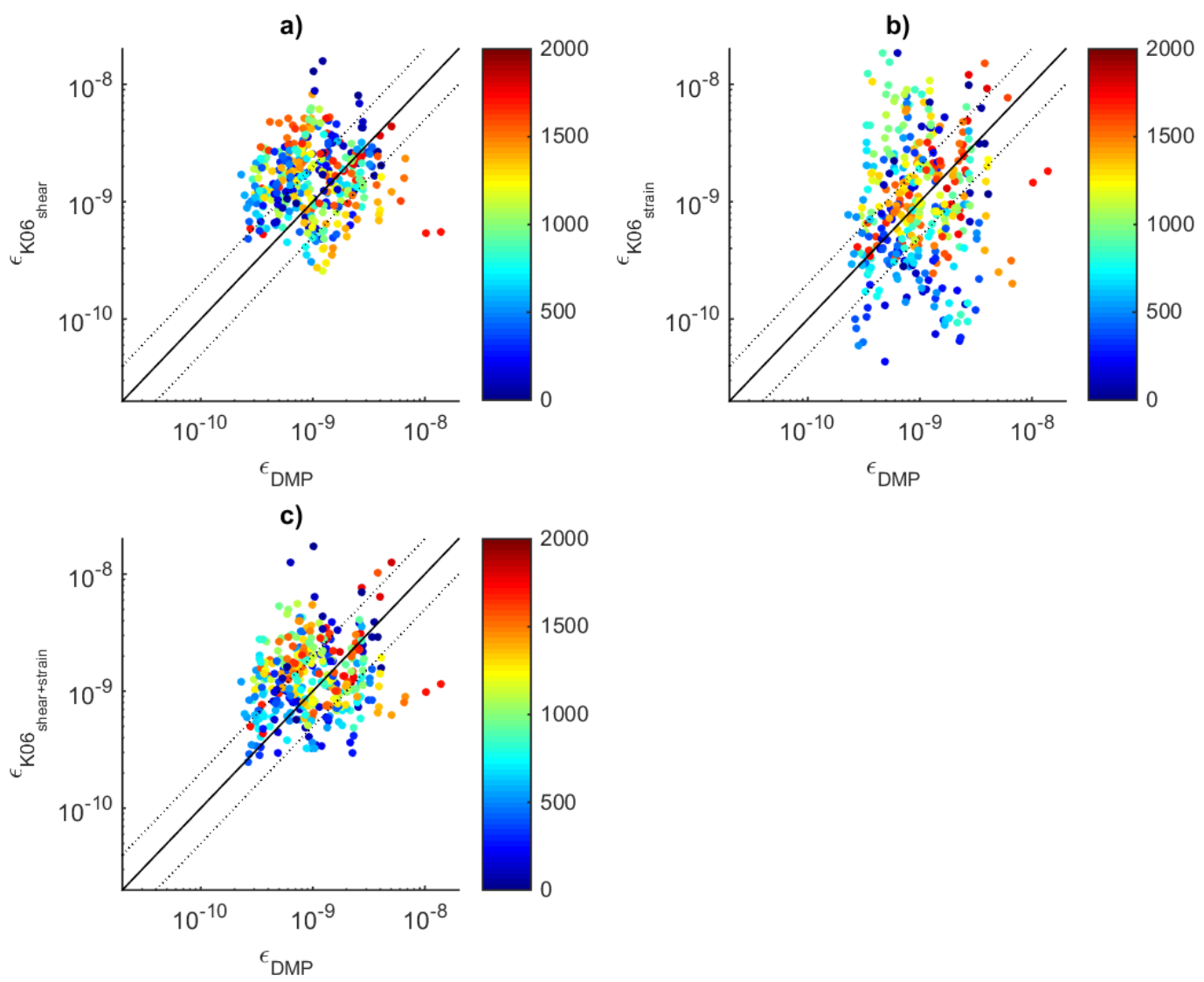

Figure 12: Scatter plots of parameterizations as a function of $\epsilon_{D M P}$ for: shear only based $\epsilon_{K 06-S N}$ (a), strain only based $\epsilon_{K 06-S N}$ (b) and shear+strain equal to $\epsilon_{K 06-S N}$ (c). The two dotted lines delimit the area where the ratio between $\epsilon$ from the parameterizations and $\epsilon_{D M P}$ is less than 2. The colorbar denotes the height above bottom. 

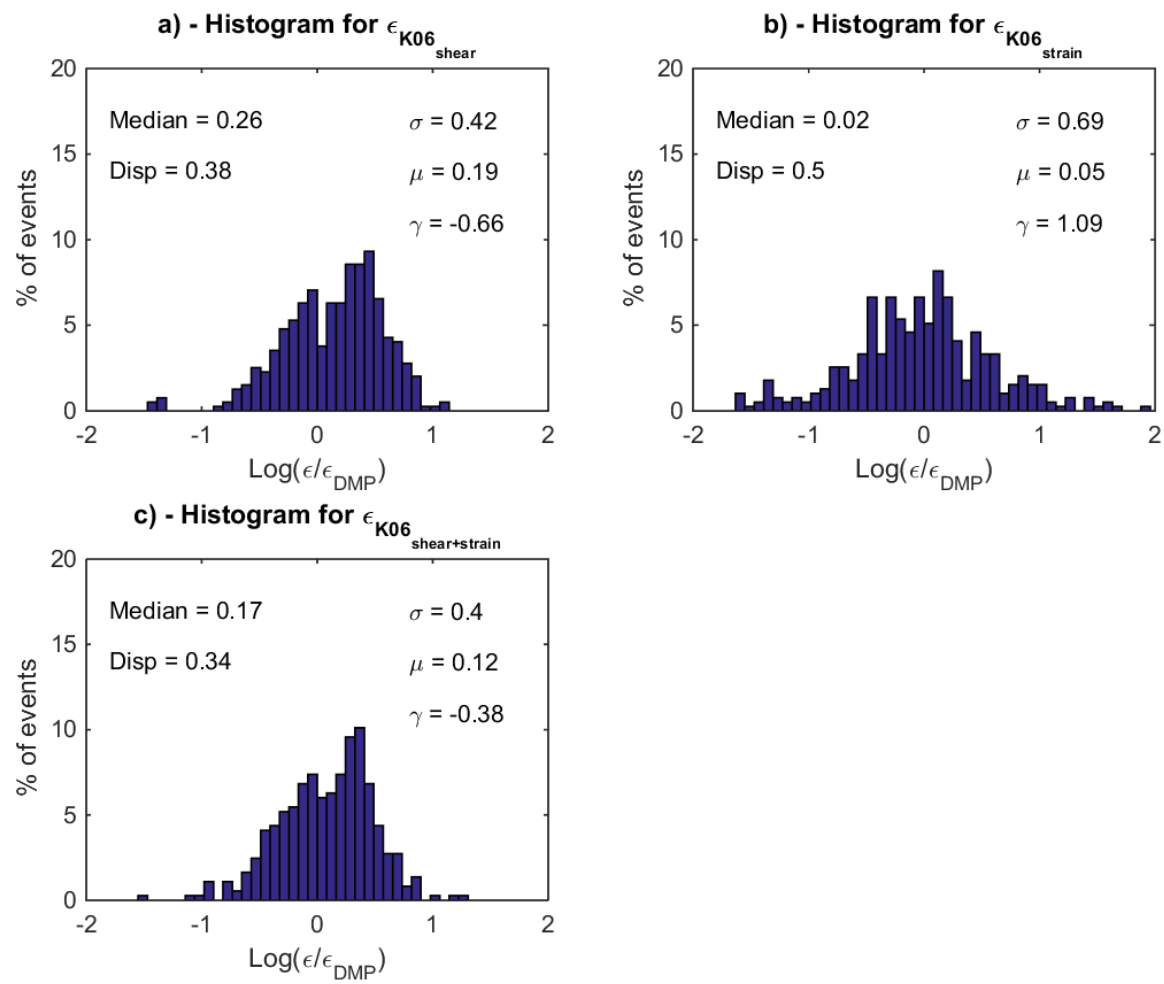

Figure 13: Histogram of the logarithm of the ratio between $\epsilon$ parameterized and $\epsilon_{D M P}$ observed for the 3 following parameterizations: shear only based $\epsilon_{K 06-S N}$ (a), strain only based $\epsilon_{K 06-S N}$ (b) and shear+strain equal to $\epsilon_{K 06-S N}$ (c). The x-axis is the logarithm of the ratio and the $\mathrm{y}$-axis is the percentage of points with this ratio. Mean value, $\mu$, standard deviation, $\sigma$, and skewness, $\gamma$ are indicated in each case. 

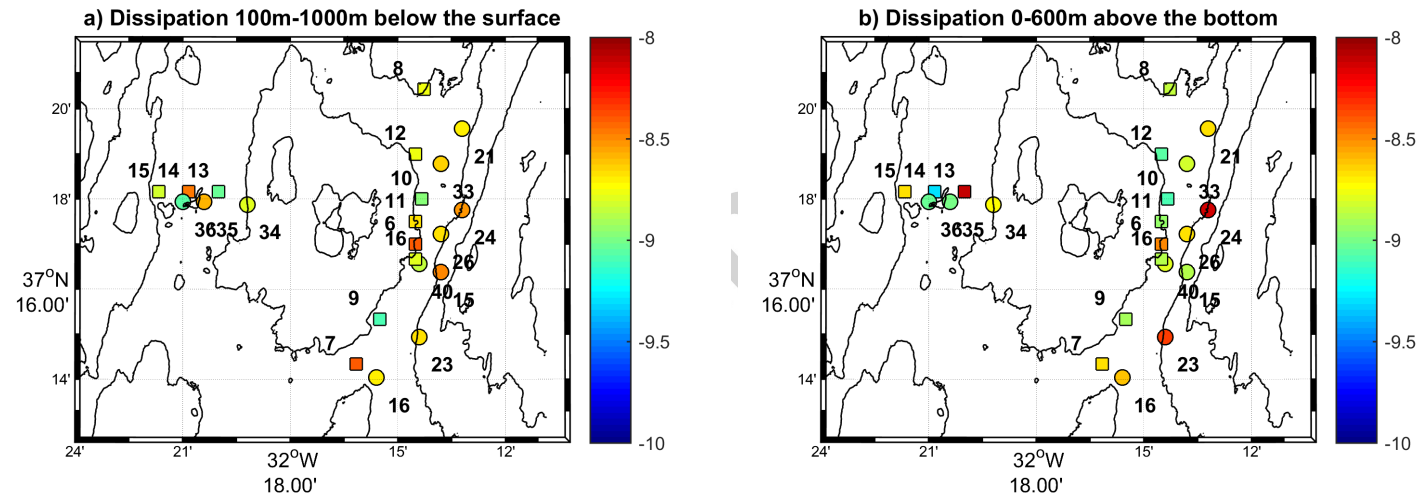

Figure 14: Dissipation parameterized using K06 with an upper bound signal $/$ noise $=5$, $\epsilon_{K 06-S N}$ (circles) and dissipation measured by the DMP (squares with black edge) averaged from $100 \mathrm{~m}$ below the surface to $1000 \mathrm{~m}$ depth (a) and from the bottom to $600 \mathrm{~m}$ above the bottom (b). 